OPEN ACCESS

Edited by: Elodie Segura, Institut Curie, France

Reviewed by: Stephanie Hugues, Université de Genève, Switzerland Justine Mintern,

The University of Melbourne, Australia

${ }^{*}$ Correspondence: Christian Münz christian.muenz@uzh.ch

Specialty section: This article was submitted to Antigen Presenting Cell Biology,

a section of the journal

Frontiers in Immunology

Received: 03 February 2022 Accepted: 15 February 2022

Published: 04 March 2022

Citation:

Münz C (2022) Canonical and Non-Canonical Functions of the Autophagy Machinery in MHC Restricted Antigen Presentation.

Front. Immunol. 13:868888 doi: 10.3389/fimmu.2022.868888

\section{Canonical and Non-Canonical Functions of the Autophagy Machinery in MHC Restricted Antigen Presentation}

\author{
Christian Münz * \\ Viral Immunobiology, Institute of Experimental Immunology, University of Zürich, Zürich, Switzerland
}

Macroautophagy delivers cytoplasmic constituents for lysosomal degradation. Since major histocompatibility complex (MHC) class II molecules sample peptides after lysosomal degradation for presentation to $\mathrm{CD} 4^{+} \mathrm{T}$ cells, it was originally described that these peptides can also originate from macroautophagy substrates. In recent years it has become clear that in addition to this canonical function of the macroautophagy machinery during $\mathrm{MHC}$ class II restricted antigen presentation at least parts of this machinery are also used to regulate phagocytosis of antigens, degradation of $\mathrm{MHC}$ class I molecules, and unconventional secretion of antigens in extracellular vesicles, including virus particles. This review discusses how both canonical and non-canonical functions of the macroautophagy machinery influence antigen presentation on $\mathrm{MHC}$ class I and II molecules to $\mathrm{CD}^{+}$and $\mathrm{CD}^{+}{ }^{+} \mathrm{T}$ cells. A better understanding of the molecular mechanisms by which the macroautophagy machinery is distributed between its canonical and non-canonical functions should allow targeting of antigens to these different pathways to influence $\mathrm{MHC}$ restricted presentation during vaccination against infectious diseases and tumors.

\footnotetext{
Keywords: LC3-associated phagocytosis, unconventional secretion, extracellular vesicles, T cells, macroautophagy
}

\section{INTRODUCTION ON AUTOPHAGY}

Autophagy, or self-eating, summarizes several pathways by which a cell can degrade its constituents in lysosomes (1-3). This group of pathways includes macroautophagy, microautophagy and chaperone-mediated autophagy, These pathways target cytosolic protein aggregates, cell organelles, intracellular pathogens and even surface receptors for degradation. In recent years it has become clear that the macroautophagy machinery is also used for non-canonical membrane trafficking events. The role of both canonical and non-canonical functions of the macroautophagy machinery for antigen processing and presentation to the immune system will be discussed in this review.

During macroautophagy its machinery of more than 40 autophagy related (ATG) proteins can be subdivided in different complexes $(1,2)$. A first protein kinase complex with ULK1 at its core and including ATG13 and FIP200 integrates signals of nutrient starvation to increase autophagy. For this purpose, depletion of ATP and an associated increase in AMP stimulates the AMP-activated protein 
kinase (AMPK) that in turn increases ULK1 function. Vice versa, nutrient availability stimulates the mechanistic target of rapamycin (mTOR) complex that inhibits ULK1 by phosphorylation. ULK1 modulates macroautophagy by phosphorylating many components of the macroautophagy machinery, including the type III phosphatidylinositol 3-kinase (PI3K) complex with VPS34 at its core and Beclin-1 and ATG14 as additional components (4). This complex phosphorylates membranes to which ubiquitin-like molecules will be covalently coupled. While yeast contains with ATG8 only one of these, human cells have six orthologues (LC3A, LC3B, LC3C, GABARAP, GABARAP-L1 and GABARAP-L2). These molecules are processed from their pro-forms by the cysteine proteases of the ATG4 family (ATG4A, ATG4B, ATG4C and ATG4D in humans). They then can be coupled to phosphatidylethanolamine or phosphatidylserine in membranes, converting for example LC3B-I into lipidated LC3B-II (5). This is performed by a ligase composed of ATG16L1, ATG5 and ATG12. ATG12 is another ubiquitin-like molecule that is covalently conjugated to ATG5 by ATG10 after activation by ATG7. Similarly, the ATG8 family is activated by ATG7 and conjugated by ATG3 before it is ligated to membranes via ATG16L1/ATG5/ ATG12. The ATG8 ligase complex is recruited to these membranes by ATG16L1 binding to WIPI proteins that themselves are recruited to PI3P labelled membranes, generated by the VPS34 complex. ATG2 stabilized membrane channels and ATG9 containing membrane vesicles extend the ATG8 coupled membranes to the isolation membrane or phagophore that forms around macroautophagy substrates $(6,7)$. These substrates are linked to ATG8 or its human orthologues in the emerging isolation membrane by autophagy receptors, including p62, optineurin, NBR1, NDP52 and TAX1BP1 $(8,9)$. Once completed and engulfing the cargo as a double-membrane surrounded vesicle, this autophagosome travels along microtubules to fuse with late endosomes or lysosomes. Most ATG8 molecules are recycled from the outer autophagosomal membrane by ATG4 proteases (10). Fusion with late endosomes and lysosomes is then mediated by a machinery that includes syntaxin 17 and YKT6 (11, 12). The resulting autolysosome then degrades cargo and inner membrane of the fused autophagosome. Therefore, turnover of ATG8-II or its human orthologues including LC3B-II of the inner autophagosomal membrane, as well as degradation of the autophagy receptors such as p62 can be used to monitor flux through the macroautophagy pathway (13). The degradation products such as amino acids are exported from the autolysosome and thereby recycled by the cell. Therefore, macroautophagy delivers cellular components to lysosomal degradation which is monitored by the immune system for the presence of pathogen derived peptide sequences by MHC class II restricted antigen presentation.

\section{INTRACELLULAR ANTIGEN PROCESSING BY MACROAUTOPHAGY}

Major histocompatibility complex (MHC) class II molecules present peptides of around 15 amino acids with a core binding sequence of 9 amino acids to helper $\mathrm{CD} 4^{+} \mathrm{T}$ cells (14). They sample these peptides from lysosomal degradation products in late endosomal MHC class II compartments (MIICs) (Figure 1). MHC class II molecules reach MIICs complexed to the chaperone invariant chain (Ii) which is then also degraded in MIICs. HLA-DM (H2-M in mice) then exchanges the last Ii remnant for peptides that bind with high affinity to the respective MHC class II molecules before these are displayed on the cell surface to $\mathrm{CD} 4^{+} \mathrm{T}$ cells.

Macroautophagy and chaperone-mediated autophagy can deliver antigens to MIICs for loading onto MHC class II molecules and $\mathrm{CD}^{+}{ }^{+} \mathrm{T}$ cells stimulation (15-19) (Figure 1). These pathways allow sampling of both cytosolic and nuclear antigens (20-22). MHC class II ligands include also ATG8 orthologues, like LC3B, GABARAP and GABARAP-L1, as well as autophagy receptors, such as TAX1BP1 $(19,23)$. This pathway might be especially important in cell types with limited phagocytic activity such as B, epithelial and endothelial cells. Along these lines, nuclear antigen 1 (EBNA1) of the Epstein Barr virus (EBV) was found to be processed via macroautophagy in EBV transformed B cells for presentation on MHC class II molecules to $\mathrm{CD}^{+} \mathrm{T}$ cells $(16,20)$. Indeed, one of the peptidomes that identified ATG8 orthologues and autophagy receptors as sources of MHC class II ligands was eluted from EBV transformed B cells (19). EBV activates these B cells with its oncogene latent membrane protein 1 (LMP1), stimulating macroautophagy (24). Such LMP1 activated B cells have recently been shown to efficiently stimulate $\mathrm{CD} 4^{+} \mathrm{T}$ cells against tumor associated antigens (TAAs) (25). In this study, LMP1 expression resulted in TAA expression and these TAAs were then intracellularly processed onto MHC class II molecules. Such LMP1 expressing B cells were capable to stimulate TAA specific cytotoxic $\mathrm{CD} 4^{+} \mathrm{T}$ cells and even prime such $\mathrm{CD} 4^{+} \mathrm{T}$ cell specificities from tumor patients. These studies suggest that $\mathrm{B}$ cells might utilize autophagic pathways to load their MHC class II molecules and after proper activation of these antigen presenting cells, including by EBV infection or LMP1 expression, allows them to potently stimulate even cytotoxic $\mathrm{CD} 4^{+} \mathrm{T}$ cell responses.

Additional cell types that might depend on autophagic pathways to load their MHC class II molecules are epithelial and endothelial cells. In particular, thymic epithelial cells that are involved in $\mathrm{T}$ cell education and central tolerance have high constitutive macroautophagy (26). Autophagosomes fuse in these cells with MIICs (27). ATG5 deficient thymic epithelial cells present an altered peptide repertoire on their MHC class II molecules (26). This results in changed positive and negative $\mathrm{CD}^{+} \mathrm{T}$ cell selection in the thymus, diminishing positive selection of some $\mathrm{T}$ cell receptor specificities and resulting in an autoreactive $\mathrm{T}$ cell repertoire. Targeting antigens for macroautophagy in medullary thymic epithelial cells via fusion with LC3B, a strategy that has been used to increase MHC class II presentation for a variety of viral and tumor antigens $(17,28-31)$, leads to negative selection of $\mathrm{CD}^{+} \mathrm{T}$ cells that are specific for the respective antigens (32). In addition to this role in central tolerance, endogenous antigen processing via macroautophagy 


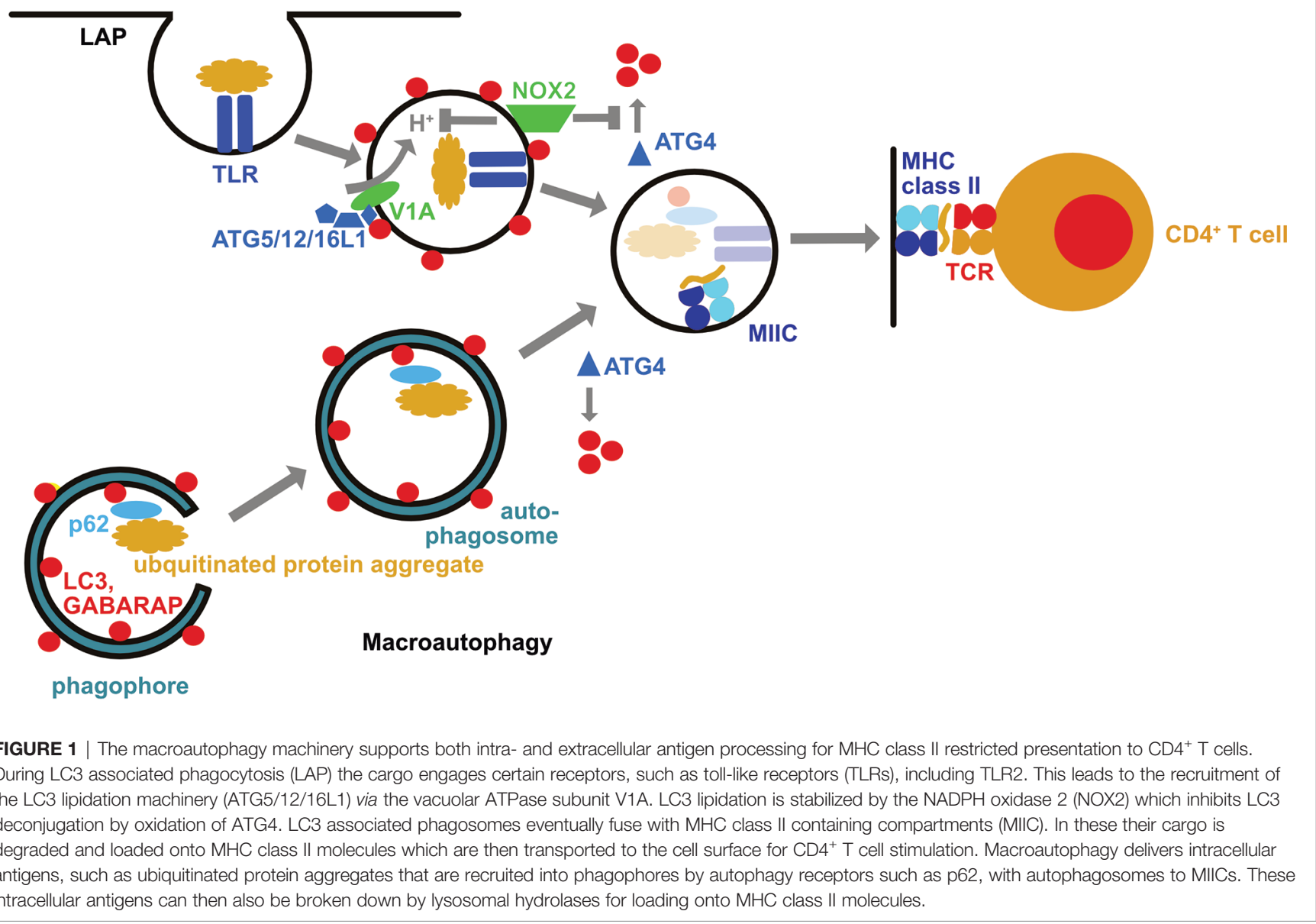

might also be important for peripheral tolerance and regulatory $\mathrm{CD}^{+} \mathrm{T}$ cell stimulation. Along these lines lymphatic endothelial cells express MHC class II molecules to stimulate regulatory $\mathrm{CD}^{+} \mathrm{T}$ cells (33-36). Autophagosomes fuse with MIICs in these cells (36). Loss of ATG5 compromises regulatory $\mathrm{T}$ cell proliferation and phenotype, and results in exacerbated collagen induced arthritis with Th17 infiltrations (36). The macroautophagic machinery is then required in dendritic cells to maintain regulatory $\mathrm{CD}^{+} \mathrm{T}$ cell function (37). Vice versa, regulatory $\mathrm{CD}^{+} \mathrm{T}$ cells down-modulate the macroautophagy machinery in dendritic cells to prevent autoimmunity (38). Therefore, macroautophagic self-antigen processing for $\mathrm{MHC}$ class II presentation in lymphatic endothelial cells and the macroautophagy machinery in dendritic cells might sustain regulatory $\mathrm{CD} 4^{+} \mathrm{T}$ cell function in tissues to prevent autoimmunity.

\section{EXTRACELLULAR ANTIGEN PROCESSING BY LC3-ASSOCIATED PHAGOCYTOSIS}

In addition to this canonical function of the macroautophagy machinery for intracellular antigen presentation on MHC class II molecules, components of this machinery support also extracellular antigen presentation to $\mathrm{CD}^{+} \mathrm{T}$ cells (39-46). Revealing characteristics of this non-canonical function of the macroautophagy machinery, it was already noted in yeast deficient for ATG4 and transgenic for the processed ATG8-I, allowing therefore conjugation but not deconjugation of ATG8 at membranes, that ATG8 can be coupled to endosomal, vacuolar and endoplasmic reticulum membranes (47). Along these lines it has been shown that ATG8 orthologues, including LC3B, can also be conjugated to the cytosolic side of phagosomes during LC3-associated phagocytosis (LAP) $(41,48)$ (Figure 1). In contrast to macroautophagy, the ULK1 complex is not required for LAP, but ATG16L1 is recruited to phagosomes via its WD40 domain, and assembly of the NADPH oxidase 2 (NOX2) at this membrane as well as its function is required for LAP $(41,44,49)$. NOX2 assembly is facilitated by the engagement of pathogen associated molecular pattern (PAMP) receptors during LAP cargo uptake. Along these lines engagement of toll-like receptor 2 (TLR2), of the C-type lectin Dectin-1, of Fc receptors and of the phosphatidylserine receptor TIM4 have been described to stimulate LAP $(40,41,48,50)$. The function of NOX2 during LAP could at least be twofold. NOX2 has been reported to neutralize the $\mathrm{pH}$ of maturing phagosomes via its reactive oxygen species (ROS) production (51), and $\mathrm{pH}$ 
neutralization during endosome maturation seems to accumulate components of the vesicular ATPase at these vesicles that then recruits ATG16L1 via its WD40 domain (52) (Figure 1). The ATG16L1, ATG5 and ATG12 dependent conjugation of LC3B at membranes of such endosomes with compromised acidification seems to preferentially occur to phosphatidylserine (5). A second function of NOX2 produced ROS is the regulation of LC3B deconjugation by ATG4B from phagosomal membranes (46) (Figure 1). It has been shown that oxidation inhibits ATG4 activity, and even leads to its aggregation (46, 53-55). Accordingly, phagosomes with the highest ROS production sustained LC3B conjugation, and presented with delayed acidification and lysosome fusion (41, $46,51)$. ROS insensitive ATG4B was able to deconjugate LC3B and inhibit LAP (46). Even so these molecular features of NOX2 and LC3B associated phagosomes are most consistent with delayed endocytosed cargo degradation, as has been observed for human myeloid cells $(41,46)$, LAP supports more rapid endocytosed pathogen degradation in mouse myeloid cells (48$50,56)$. In the absence of efficient lysosomal fusion LAP directs phagosomes to other endosomal compartments, such as TLR containing endosomes, as observed in plasmacytoid dendritic cells and lung epithelial cells $(57,58)$.

Alternatively, LAP directs its cargo also for efficient $\mathrm{MHC}$ class II restricted antigen presentation (39-46). This has been demonstrated for bacterial, yeast, model, tumor, and autoantigens. Diminished $\mathrm{CD} 4^{+} \mathrm{T}$ cell stimulation in the absence of LAP supported MHC class II restricted antigen presentation by dendritic cells leads also to an amelioration of experimental autoimmune encephalomyelitis (EAE), an autoimmune CNS disease in mice, after adoptive transfer of autoimmune $\mathrm{CD} 4^{+} \mathrm{T}$ cells into mice that are either deficient in ATG5 or $\operatorname{NOX} 2(43,59,60)$. However, LAP in microglia, the resident macrophages of the brain, does not seem to be required for this LAP dependent autoantigen presentation to elicit EAE after autoimmune $\mathrm{CD}^{+} \mathrm{T}$ cell transfer (61). In addition, a LAPlike pathway supports bacterial outer membrane vesicle (OMV) processing for the stimulation of regulatory $\mathrm{CD} 4^{+} \mathrm{T}$ cells in the mouse gut (42). Expression of ATG4B that is insensitive to NOX2 produced ROS inhibits endocytosed yeast antigen presentation on MHC class II molecules by human macrophages to Candida albicans specific CD ${ }^{+} \mathrm{T}$ cells (46). Therefore, the non-canonical role of the macroautophagy machinery during phagocytosis (LAP) redirects extracellular antigens for more efficient antigen presentation on MHC class II molecules to $\mathrm{CD} 4^{+} \mathrm{T}$ cells.

\section{ATTENUATION OF MHC CLASS I RESTRICTED ANTIGEN PRESENTATION BY THE MACROAUTOPHAGY MACHINERY}

In contrast to MHC class II ligands, peptides that are presented by MHC class I molecules originate primarily from proteasomal degradation in cytosol and nucleus (62) (Figure 2). The peptides are then translocated by the transporter associated with antigen presentation (TAP) into the endoplasmic reticulum (ER) where they get loaded onto MHC class I molecules which is cotranslationally inserted into the ER. Once a high affinity octaor nonameric peptide has been inserted into the peptide binding groove, the MHC class I loading complex disassembles and the MHC class I plus peptide complex is transported to the cell surface for surveillance by $\mathrm{CD} 8^{+} \mathrm{T}$ cells.

In mice with compromised macroautophagy in dendritic cells (ATG5, ATG7 or ATG16L1 deficiency) hyperreactive $\mathrm{CD}^{+} \mathrm{T}$ cell responses were noted $(63,64)$. These result in part from stabilized MHC class I molecules on the cell surface of dendritic

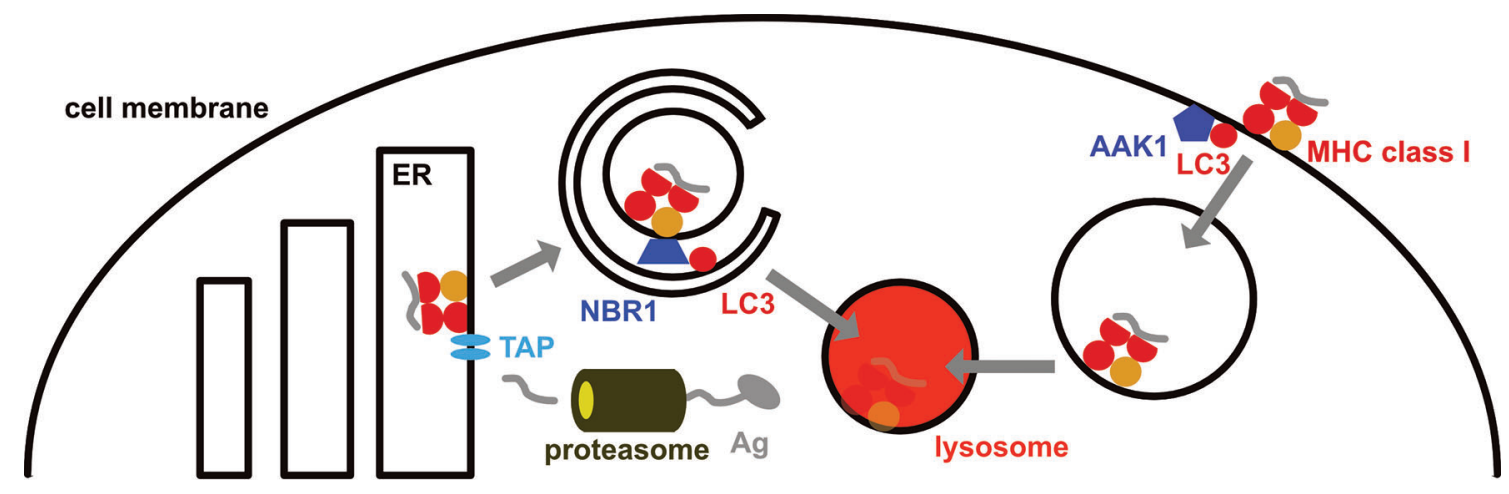

FIGURE 2 | MHC class I surface expression is down-regulated by the macroautophagy machinery. MHC class I molecules are loaded in the endoplasmic reticulum (ER), primarily with peptides that originate from proteasomal degradation and are then imported into the ER via the transporter associated with antigen presentation (TAP). On their way to the cell membrane from the ER, MHC class I molecules are targeted for macroautophagy by the autophagy receptor NBR1, resulting in their lysosomal degradation in pancreatic ductal adenocarcinoma (PDAC) cells. In addition, LC3 lipidation recruits parts of the internalization machinery to MHC class I molecules at the cell membrane, including AP2 associated kinase 1 (AAK1). This leads to a more rapid internalization and degradation of MHC class I molecules in dendritic cells. 
cells, resulting in their accumulation and increased $\mathrm{CD} 8^{+} \mathrm{T}$ cell stimulation (63). This MHC class I accumulation was due to decreased internalization (Figure 2). LC3 lipidation was required for recruitment of parts of the MHC class I internalization machinery to MHC class I molecules, including AP2 associated kinase 1 (AAK1) (63). In the absence of AAK1 mediated MHC class I internalization dendritic cells stimulated stronger influenza A virus specific $\mathrm{CD}^{+} \mathrm{T}$ cell responses in vitro and in vivo. These inversely correlated with influenza A viral loads after infection. Similarly, higher lymphocytic choriomeningitis virus (LCMV) specific immune responses were detected in the absence of LC3 lipidation. In addition, the macroautophagy machinery supports degradation of extracellular antigen storage compartments in dendritic cells and thereby also compromises MHC class I restricted antigen cross-presentation (65). Enhanced internalization by LC3 lipidation extends also to the non-classical MHC class I molecule CD1d (66). CD1d presents glycolipids to invariant NKT cells. In the absence of ATG5 of dendritic cells CD1d levels are elevated on dendritic cells and NKT cell responses are more efficiently stimulated in vitro and in vivo. This leads to attenuated infection with the NKT cell sensitive bacterial pathogen Sphingomonas paucimobilis in mice. Thus, the LC3 lipidation complex negatively regulates surface expression of classical and non-classical MHC class I molecules on dendritic cells, resulting in diminished $\mathrm{CD} 8^{+} \mathrm{T}$ and NKT cell stimulation.

Another cell type in which the autophagy machinery downregulates $\mathrm{MHC}$ class I molecules are pancreatic ductal adenocarcinoma (PDAC) cells $(67,68)$. PDAC cells express low levels of surface MHC class I molecules which are diverted for lysosomal degradation by NBR1 dependent macroautophagy (67) (Figure 2). Macroautophagy inhibition by ATG3 downregulation or lysosomal degradation attenuation restores MHC class I surface expression. Together with immune check-point blockade treatment by antibody blocking of PD-1 and CTLA-4, macroautophagy inhibition allows for efficient $\mathrm{CD}^{+} \mathrm{T}$ cell stimulation in PDAC tumors and decreased pancreatic cancer growth in mice. This macroautophagy dependent degradation of MHC class I molecules in PDAC cells seems to be stimulated by autocrine progranulin secretion of the cancer cells (68). Antibody mediated blocking of progranulin restores $\mathrm{MHC}$ class I expression on PDAC cells and leads to attenuated pancreatic cancer growth in mice. Thus, the macroautophagy machinery targets $\mathrm{MHC}$ class I molecules for lysosomal degradation in PDAC cells, allowing these to escape $\mathrm{CD}^{+} \mathrm{T}$ cell mediated immune control.

\section{ANTIGEN SECRETION WITH THE ASSISTANCE OF THE MACROAUTOPHAGY MACHINERY}

In addition to influencing the trafficking of MHC class I molecules in dendritic and tumor cells, the autophagy machinery has also been implicated in releasing antigens for optimal cross-presentation on MHC class I molecules $(69,70)$.
Release of extracellular vesicles that carry antigens for efficient cross-presentation was found to be enhanced by inhibition of lysosomal degradation $(71,72)$. Furthermore, it was noted that these extracellular vesicles can be efficiently processed for antigen presentation on MHC class I and II molecules $(73,74)$. Inhibition of lysosomal acidification or of the fusion machinery between autophagosomes and lysosomes leads to the release of vesicles that contain autophagy receptors, such as p62 and NBR1 $(75,76)$. These receptors recruit most likely ubiquitinated protein aggregates of both long- and short-lived proteins (71) into autophagosomes whose inner membrane is then released for unconventional secretion after autophagosome fusion with multivesicular bodies (MVBs) and successive exocytosis from MVBs. This pathway of antigen transfer that can be enhanced upon inhibition of autophagosome degradation in lysosomes is most likely also used by physiological substrates, such as acyl coenzyme A-binding protein (ACBP) in yeast and IL-1 $\beta$ in mammalian cells (77-80). Furthermore, it might be related to secretory lysosomes $(81,82)$. Thus, the canonical functions of the macroautophagy machinery might select ubiquitinated antigens with autophagy receptors into autophagosomes which fuse with MVBs, followed by exocytosis of the inner autophagosomal membrane and its content to become extracellular vesicles. The contained antigens are efficiently presented on MHC class I and II molecules of bystander antigen presenting cells.

In addition to this secretion of inner autophagosomal membranes, the macroautophagy machinery supports direct recruitment of LC3 binding proteins at the limiting membrane of MVBs for unconventional secretion in their intravesicular bodies (83). This pathway targets RNA binding proteins (RBPs), such as heterogeneous nuclear ribonucleoprotein K (HNRNPK) and scaffold-attachment factor B (SAFB), by direct interaction with LC3 at the limiting MVB membrane that then invaginates to become an intravesicular body containing RBPs and their RNA. This membrane invagination requires neutral sphingomyelinase 2 (nSMase2), and the factor associated with nSMase 2 activity (FAN) that directly interacts with LC3. Thus, this second unconventional secretion pathway that uses the LC3 conjugation machinery delivers LC3 interacting RBPs for release in extracellular vesicles.

Viruses have been described to carry lipidated ATG8 orthologues, including LC3B-II, in their envelope or pseudoenvelope (84-88). Indeed, inhibition of the LC3 conjugation machinery, including of ATG5, ATG12 and ATG16L1, inhibit the non-lytic release of both herpes and picornaviruses. Which of the two above outlined unconventional secretion pathways these viruses, however, use to acquire LC3 coupled membranes remains unclear because the role of autophagy receptors versus viral proteins that might directly interact with LC3 in this process have not been elucidated. Thus, the macroautophagy machinery supports at least two different pathways of unconventional secretion in extracellular vesicles. These are used to efficiently transfer antigens for MHC class I and II restricted presentation, but are also hijacked by pathogens, mainly viruses, for their release. 


\section{CONCLUSIONS} AND FUTURE DIRECTIONS

In recent years it was realized that parts of the macroautophagy machinery are used in modular form for additional membrane trafficking events, including antigen phagocytosis, surface receptor endocytosis, and exocytosis of extracellular vesicles. All of these additional pathways intersect with MHC class I and II restricted antigen presentation for $\mathrm{CD}^{+}$and $\mathrm{CD} 4^{+} \mathrm{T}$ cell stimulation, respectively. While for some of these pathways, like LAP, molecular interactors that recruit only parts of the macroautophagy machinery, such as ATG16L1 interaction with the vesicular ATPase and NOX2 regulation of ATG4, are starting to be defined $(46,52)$, additional information needs to be gathered on how the macroautophagy machinery is distributed between the different membrane trafficking events that it regulates.

Such detailed information seems necessary in order to separately influence the different pathways that are regulated by the macroautophagy machinery and uncouple its pro- and anti-immunogenic functions, e.g. avoiding MHC class I degradation but maintaining enhanced MHC class II antigen presentation during immune responses. Along these lines, antigen targeting via different autophagy receptors or different ATG8 orthologues could be further explored, as has been initially

\section{REFERENCES}

1. Münz C. Non-Canonical Roles of Autophagy Proteins in Endocytosis and Exocytosis. Biochem Soc Trans (2021) 49:2841-51. doi: 10.1042/BST20210811

2. Klionsky DJ, Petroni G, Amaravadi RK, Baehrecke EH, Ballabio A, Boya P, et al. Autophagy in Major Human Diseases. EMBO J (2021) 40:e108863. doi: 10.15252/embj.2021108863

3. Li Z, Nakatogawa H. Degradation of Nuclear Components via Different Autophagy Pathways. Trends Cell Biol (2022). doi: 10.1016/j.tcb.2021.12.008

4. Hu Z, Raucci S, Jaquenoud M, Hatakeyama R, Stumpe M, Rohr R, et al. Multilayered Control of Protein Turnover by TORC1 and Atg1. Cell Rep (2019) 28:3486-96.e6. doi: 10.1016/j.celrep.2019.08.069

5. Durgan J, Lystad AH, Sloan K, Carlsson SR, Wilson MI, Marcassa E, et al. Non-Canonical Autophagy Drives Alternative ATG8 Conjugation to Phosphatidylserine. Mol Cell (2021) 81:2031-40.e8. doi: 10.1016/ j.molcel.2021.03.020

6. Matoba K, Kotani T, Tsutsumi A, Tsuji T, Mori T, Noshiro D, et al. Atg9 is a Lipid Scramblase That Mediates Autophagosomal Membrane Expansion. Nat Struct Mol Biol (2020) 27:1185-93. doi: 10.1038/s41594-020-00518-w

7. Osawa T, Kotani T, Kawaoka T, Hirata E, Suzuki K, Nakatogawa H, et al. Atg2 Mediates Direct Lipid Transfer Between Membranes for Autophagosome Formation. Nat Struct Mol Biol (2019) 26:281-8. doi: 10.1038/s41594-0190203-4

8. Lamark T, Johansen T. Mechanisms of Selective Autophagy. Annu Rev Cell Dev Biol (2021) 37:143-69. doi: 10.1146/annurev-cellbio-120219-035530

9. Zellner S, Schifferer M, Behrends C. Systematically Defining Selective Autophagy Receptor-Specific Cargo Using Autophagosome Content Profiling. Mol Cell (2021) 81:1337-54.e8. doi: 10.1016/j.molcel.2021.01.009

10. Agrotis A, Pengo N, Burden JJ, Ketteler R. Redundancy of Human ATG4 Protease Isoforms in Autophagy and LC3/GABARAP Processing Revealed in Cells. Autophagy (2019) 15:976-97. doi: 10.1080/ 15548627.2019.1569925

11. Itakura E, Kishi-Itakura C, Mizushima N. The Hairpin-Type Tail-Anchored SNARE Syntaxin 17 Targets to Autophagosomes for Fusion With Endosomes/ Lysosomes. Cell (2012) 151:1256-69. doi: 10.1016/j.cell.2012.11.001 reported for LC3B fusion antigens $(17,28-31)$. Combined with specific targeting for intracellular expression of such targeted antigens in professional antigen presenting cells such as dendritic or B cells by suitable viral vectors or liposome encapsulated mRNA, such approaches could refine vaccination against infectious diseases and tumors.

\section{AUTHOR CONTRIBUTIONS}

The author confirms being the sole contributor of this work and has approved it for publication.

\section{FUNDING}

Research in my laboratory is financially supported by Cancer Research Switzerland (KFS-4962-02-2020), HMZ ImmunoTargET of the University of Zurich, the Cancer Research Center Zurich, the Sobek Foundation, the Swiss Vaccine Research Institute, the Swiss MS Society (2021-09), Roche, Novartis, Innosuisse (52533.1), and the Swiss National Science Foundation (310030_204470/1, 310030L_197952/1 and CRSII5_180323). The funders were not involved in the writing of this article or the decision to submit it for publication.

12. Matsui T, Jiang $\mathrm{P}$, Nakano S, Sakamaki Y, Yamamoto H, Mizushima N Autophagosomal YKT6 is Required for Fusion With Lysosomes Independently of Syntaxin 17. J Cell Biol (2018) 217:2633-45. doi: 10.1083/ jcb.201712058

13. Klionsky DJ, Abdel-Aziz AK, Abdelfatah S, Abdellatif M, Abdoli A, Abel S, et al. Guidelines for the Use and Interpretation of Assays for Monitoring Autophagy (4th Edition). Autophagy (2021) 17:1-382. doi: 10.1080/ 15548627.2020.1797280

14. Cresswell P. A Personal Retrospective on the Mechanisms of Antigen Processing. Immunogenetics (2019) 71:141-60. doi: 10.1007/s00251-01801098-2

15. Nimmerjahn F, Milosevic S, Behrends U, Jaffee EM, Pardoll DM, Bornkamm GW, et al. Major Histocompatibility Complex Class II-Restricted Presentation of a Cytosolic Antigen by Autophagy. Eur J Immunol (2003) 33:1250-9. doi: $10.1002 /$ eji.200323730

16. Paludan C, Schmid D, Landthaler M, Vockerodt M, Kube D, Tuschl T, et al Endogenous MHC Class II Processing of a Viral Nuclear Antigen After Autophagy. Science (2005) 307:593-6. doi: 10.1126/science.1104904

17. Schmid D, Pypaert M, Münz C. MHC Class II Antigen Loading Compartments Continuously Receive Input From Autophagosomes. Immunity (2007) 26:79-92. doi: 10.1016/j.immuni.2006.10.018

18. Zhou D, Li P, Lott JM, Hislop A, Canaday DH, Brutkiewicz RR, et al. Lamp-2a Facilitates MHC Class II Presentation of Cytoplasmic Antigens. Immunity (2005) 22:571-81. doi: 10.1016/j.immuni.2005.03.009

19. Dengjel J, Schoor O, Fischer R, Reich M, Kraus M, Muller M, et al. Autophagy Promotes MHC Class II Presentation of Peptides From Intracellular Source Proteins. Proc Natl Acad Sci USA (2005) 102:7922-7.

20. Leung CS, Haigh TA, Mackay LK, Rickinson AB, Taylor GS. Nuclear Location of an Endogenously Expressed Antigen, EBNA1, Restricts Access to Macroautophagy and the Range of CD4 Epitope Display. Proc Natl Acad Sci U.S.A. (2010) 107:2165-70.

21. Riedel A, Nimmerjahn F, Burdach S, Behrends U, Bornkamm GW, Mautner J. Endogenous Presentation of a Nuclear Antigen on MHC Class II by Autophagy in the Absence of CRM1-Mediated Nuclear Export. Eur J Immunol (2008) 38:2090-5. doi: 10.1002/eji.200737900 
22. Perez L, McLetchie S, Gardiner GJ, Deffit SN, Zhou D, Blum JS. LAMP-2c Inhibits MHC Class II Presentation of Cytoplasmic Antigens by Disrupting Chaperone-Mediated Autophagy. I Immunol (2016) 196:2457-65. doi: 10.4049/jimmunol.1501476

23. Suri A, Walters JJ, Rohrs HW, Gross ML, Unanue ER. First Signature of Islet \{Beta\}-Cell-Derived Naturally Processed Peptides Selected by Diabetogenic Class II MHC Molecules. J Immunol (2008) 180:3849-56. doi: 10.4049/ jimmunol.180.6.3849

24. Lee DY, Sugden B. The Latent Membrane Protein 1 Oncogene Modifies B-Cell Physiology by Regulating Autophagy. Oncogene (2008) 27:2833-42. doi: 10.1038/sj.onc.1210946

25. Choi IK, Wang Z, Ke Q, Hong M, Paul DWJr., Fernandes SM, et al. Mechanism of EBV Inducing Anti-Tumour Immunity and its Therapeutic Use. Nature (2021) 590:157-62. doi: 10.1038/s41586-020-03075-w

26. Nedjic J, Aichinger M, Emmerich J, Mizushima N, Klein L. Autophagy in Thymic Epithelium Shapes the T-Cell Repertoire and Is Essential for Tolerance. Nature (2008) 455:396-400. doi: 10.1038/nature07208

27. Kasai M, Tanida I, Ueno T, Kominami E, Seki S, Ikeda T, et al. Autophagic Compartments Gain Access to the MHC Class II Compartments in Thymic Epithelium. J Immunol (2009) 183:7278-85. doi: 10.4049/jimmunol.0804087

28. Comber JD, Robinson TM, Siciliano NA, Snook AE, Eisenlohr LC. Functional Macroautophagy Induction by Influenza A Virus Without a Contribution to MHC-Class II Restricted Presentation. J Virol (2011) 85:6453-63. doi: 10.1128/JVI.02122-10

29. Coulon PG, Richetta C, Rouers A, Blanchet FP, Urrutia A, Guerbois M, et al. HIV-Infected Dendritic Cells Present Endogenous MHC Class II-Restricted Antigens to HIV-Specific CD4 ${ }^{+}$T Cells. J Immunol (2016) 197:517-32. doi: 10.4049/jimmunol.1600286

30. Fonteneau JF, Brilot F, Münz C, Gannage M. The Tumor Antigen NY-ESO-1 Mediates Direct Recognition of Melanoma Cells by $\mathrm{CD}^{+}{ }^{+} \mathrm{T}$ Cells After Intercellular Antigen Transfer. J Immunol (2016) 196:64-71. doi: 10.4049/ jimmunol.1402664

31. Jin Y, Sun C, Feng L, Li P, Xiao L, Ren Y, et al. Regulation of SIV AntigenSpecific CD4+ T Cellular Immunity via Autophagosome-Mediated MHC II Molecule-Targeting Antigen Presentation in Mice. PloS One (2014) 9:e93143. doi: 10.1371/journal.pone.0093143

32. Aichinger M, Wu C, Nedjic J, Klein L. Macroautophagy Substrates are Loaded Onto MHC Class II of Medullary Thymic Epithelial Cells for Central Tolerance. J Exp Med (2013) 210:287-300. doi: 10.1084/jem.20122149

33. Baptista AP, Roozendaal R, Reijmers RM, Koning JJ, Unger WW, Greuter M, et al. Lymph Node Stromal Cells Constrain Immunity via MHC Class II SelfAntigen Presentation. Elife (2014) 3:e04433. doi: 10.7554/eLife.04433.024

34. Nadafi R, Gago de Graca C, Keuning ED, Koning JJ, de Kivit S, Konijn T, et al. Lymph Node Stromal Cells Generate Antigen-Specific Regulatory T Cells and Control Autoreactive T and B Cell Responses. Cell Rep (2020) 30:4110-23.e4. doi: 10.1016/j.celrep.2020.03.007

35. Gkountidi AO, Garnier L, Dubrot J, Angelillo J, Harle G, Brighouse D, et al. MHC Class II Antigen Presentation by Lymphatic Endothelial Cells in Tumors Promotes Intratumoral Regulatory T Cell-Suppressive Functions. Cancer Immunol Res (2021) 9:748-64. doi: 10.1158/23266066.CIR-20-0784

36. Harle G, Kowalski C, Dubrot J, Brighouse D, Clavel G, Pick R, et al. Macroautophagy in Lymphatic Endothelial Cells Inhibits T Cell-Mediated Autoimmunity. J Exp Med (2021) 218:e20201776. doi: 10.1084/jem.20201776

37. Niven J, Madelon N, Page N, Caruso A, Harle G, Lemeille S, et al. Macroautophagy in Dendritic Cells Controls the Homeostasis and Stability of Regulatory T Cells. Cell Rep (2019) 28:21-9.e6. doi: 10.1016/ j.celrep.2019.05.110

38. Alissafi T, Banos A, Boon L, Sparwasser T, Ghigo A, Wing K, et al. Tregs Restrain Dendritic Cell Autophagy to Ameliorate Autoimmunity. J Clin Invest (2017) 127:2789-804. doi: 10.1172/JC192079

39. Lee HK, Mattei LM, Steinberg BE, Alberts P, Lee YH, Chervonsky A, et al. In Vivo Requirement for Atg5 in Antigen Presentation by Dendritic Cells. Immunity (2010) 32:227-39. doi: 10.1016/j.immuni.2009.12.006

40. Ma J, Becker C, Lowell CA, Underhill DM. Dectin-1-Triggered Recruitment of Light Chain 3 Protein to Phagosomes Facilitates Major Histocompatibility Complex Class II Presentation of Fungal-Derived Antigens. J Biol Chem (2012) 287:34149-56. doi: 10.1074/jbc.M112.382812
41. Romao S, Gasser N, Becker AC, Guhl B, Bagajic M, Vanoaica LD, et al. Essential Autophagy Proteins Stabilize Pathogen Containing Phagosomes for Prolonged MHC Class II Antigen Processing. J Cell Biol (2013) 203:757-66. doi: $10.1083 /$ jcb.201308173

42. Chu H, Khosravi A, Kusumawardhani IP, Kwon AH, Vasconcelos AC, Cunha LD, et al. Gene-Microbiota Interactions Contribute to the Pathogenesis of Inflammatory Bowel Disease. Science (2016) 352:1116-20. doi: 10.1126/ science.aad 9948

43. Keller CW, Sina C, Kotur MB, Ramelli G, Mundt S, Quast I, et al. ATGDependent Phagocytosis in Dendritic Cells Drives Myelin-Specific CD4 ${ }^{+} \mathrm{T}$ Cell Pathogenicity During CNS Inflammation. Proc Natl Acad Sci USA (2017) 114:E11228-37. doi: 10.1073/pnas.1713664114

44. Fletcher K, Ulferts R, Jacquin E, Veith T, Gammoh N, Arasteh JM, et al. The WD40 Domain of ATG16L1 is Required for its non-Canonical Role in Lipidation of LC3 at Single Membranes. EMBO J (2018) 37:e97840.

45. Oh DS, Lee HK. Autophagy Protein ATG5 Regulates CD36 Expression and Anti-Tumor MHC Class II Antigen Presentation in Dendritic Cells. Autophagy (2019) 15:2091-106. doi: 10.1080/15548627.2019.1596493

46. Ligeon LA, Pena-Francesch M, Vanoaica LD, Nunez NG, Talwar D, Dick TP, et al. Oxidation Inhibits Autophagy Protein Deconjugation From Phagosomes to Sustain MHC Class II Restricted Antigen Presentation. Nat Commun (2021) 12:1508. doi: 10.1038/s41467-021-21829-6

47. Nakatogawa H, Ishii J, Asai E, Ohsumi Y. Atg4 Recycles Inappropriately Lipidated Atg8 to Promote Autophagosome Biogenesis. Autophagy (2012) 8:177-86. doi: 10.4161/auto.8.2.18373

48. Sanjuan MA, Dillon CP, Tait SW, Moshiach S, Dorsey F, Connell S, et al. TollLike Receptor Signalling in Macrophages Links the Autophagy Pathway to Phagocytosis. Nature (2007) 450:1253-7. doi: 10.1038/nature06421

49. Martinez J, Malireddi RK, Lu Q, Cunha LD, Pelletier S, Gingras S, et al. Molecular Characterization of LC3-Associated Phagocytosis Reveals Distinct Roles for Rubicon, NOX2 and Autophagy Proteins. Nat Cell Biol (2015) 17:893-906. doi: $10.1038 / \mathrm{ncb} 3192$

50. Martinez J, Almendinger J, Oberst A, Ness R, Dillon CP, Fitzgerald P, et al. Microtubule-Associated Protein 1 Light Chain 3 Alpha (LC3)-Associated Phagocytosis is Required for the Efficient Clearance of Dead Cells. Proc Natl Acad Sci U.S.A. (2011) 108:17396-401.

51. Savina A, Jancic C, Hugues S, Guermonprez P, Vargas P, Moura IC, et al. NOX2 Controls Phagosomal pH to Regulate Antigen Processing During Crosspresentation by Dendritic Cells. Cell (2006) 126:205-18. doi: 10.1016/ j.cell.2006.05.035

52. Ulferts R, Marcassa E, Timimi L, Lee LC, Daley A, Montaner B, et al. Subtractive CRISPR Screen Identifies the ATG16L1/vacuolar ATPase Axis as Required for non-Canonical LC3 Lipidation. Cell Rep (2021) 37:109899. doi: 10.1016/j.celrep.2021.109899

53. Perez-Perez ME, Lemaire SD, Crespo JL. Control of Autophagy in Chlamydomonas Is Mediated Through Redox-Dependent Inactivation of the ATG4 Protease. Plant Physiol (2016) 172:2219-34. doi: 10.1104/ pp. 16.01582

54. Scherz-Shouval R, Shvets E, Fass E, Shorer H, Gil L, Elazar Z. Reactive Oxygen Species are Essential for Autophagy and Specifically Regulate the Activity of Atg4. EMBO J (2007) 26:1749-60. doi: 10.1038/sj.emboj.7601623

55. Zheng X, Yang Z, Gu Q, Xia F, Fu Y, Liu P, et al. The Protease Activity of Human ATG4B is Regulated by Reversible Oxidative Modification. Autophagy (2020) 16:1838-50. doi: 10.1080/15548627.2019.1709763

56. Gluschko A, Herb M, Wiegmann K, Krut O, Neiss WF, Utermohlen O, et al. The Beta2 Integrin Mac-1 Induces Protective LC3-Associated Phagocytosis of Listeria Monocytogenes. Cell Host Microbe (2018) 23:324-37.e5. doi: 10.1016/ j.chom.2018.01.018

57. Henault J, Martinez J, Riggs JM, Tian J, Mehta P, Clarke L, et al. Noncanonical Autophagy is Required for Type I Interferon Secretion in Response to DNAImmune Complexes. Immunity (2012) 37:986-97. doi: 10.1016/ j.immuni.2012.09.014

58. Wang Y, Sharma P, Jefferson M, Zhang W, Bone B, Kipar A, et al. NonCanonical Autophagy Functions of ATG16L1 in Epithelial Cells Limit Lethal Infection by Influenza A Virus. EMBO J (2021) 40:e105543. doi: 10.15252/ embj.2020105543

59. Bhattacharya A, Parillon X, Zeng S, Han S, Eissa NT. Deficiency of Autophagy in Dendritic Cells Protects Against Experimental Autoimmune 
Encephalomyelitis. J Biol Chem (2014) 289:26525-32. doi: 10.1074/ jbc.M114.575860

60. Keller CW, Kotur MB, Mundt S, Dokalis N, Ligeon LA, Shah AM, et al. CYBB/ NOX2 in Conventional DCs Controls T Cell Encephalitogenicity During Neuroinflammation. Autophagy (2021) 17:1244-58. doi: 10.1080/ 15548627.2020 .1756678

61. Srimat Kandadai K, Kotur MB, Dokalis N, Amrein I, Keller CW, Münz C, et al. ATG5 in Microglia Does Not Contribute Vitally to Autoimmune Neuroinflammation in Mice. Autophagy (2021) 17:3566-76. doi: 10.1080/ 15548627.2021.1883880

62. Dersh D, Holly J, Yewdell JW. A Few Good Peptides: MHC Class I-Based Cancer Immunosurveillance and Immunoevasion. Nat Rev Immunol (2020) 21:116-28. doi: 10.1038/s41577-020-0390-6

63. Loi M, Muller A, Steinbach K, Niven J, Barreira da Silva R, Paul P, et al. Macroautophagy Proteins Control MHC Class I Levels on Dendritic Cells and Shape Anti-Viral CD8 ${ }^{+}$T Cell Responses. Cell Rep (2016) 15:1076-87. doi: 10.1016/j.celrep.2016.04.002

64. Hubbard-Lucey VM, Shono Y, Maurer K, West ML, Singer NV, Ziegler CGK, et al. Autophagy Gene Atg16l1 Prevents Lethal T Cell Alloreactivity Mediated by Dendritic Cells. Immunity (2014) 41:579-91. doi: 10.1016/ j.immuni.2014.09.011

65. Ho NI, Camps MGM, Verdoes M, Münz C, Ossendorp F. Autophagy Regulates Long-Term Cross-Presentation by Murine Dendritic Cells. Eur J Immunol (2020) 51:835-47. doi: 10.1002/eji.202048961

66. Keller CW, Loi M, Ewert S, Quast I, Theiler R, Gannage M, et al. The Autophagy Machinery Restrains iNKT Cell Activation Through CD1D1 Internalization. Autophagy (2017) 13:1025-36. doi: 10.1080/ 15548627.2017.1297907

67. Yamamoto K, Venida A, Yano J, Biancur DE, Kakiuchi M, Gupta S, et al. Autophagy Promotes Immune Evasion of Pancreatic Cancer by Degrading MHC-I. Nature (2020) 581:100. doi: 10.1038/s41586-020-2229-5

68. Cheung PF, Yang J, Fang R, Borgers A, Krengel K, Stoffel A, et al. Progranulin Mediates Immune Evasion of Pancreatic Ductal Adenocarcinoma Through Regulation of MHCI Expression. Nat Commun (2022) 13:156. doi: 10.1038/ s41467-021-27088-9

69. Uhl M, Kepp O, Jusforgues-Saklani H, Vicencio JM, Kroemer G, Albert ML. Autophagy Within the Antigen Donor Cell Facilitates Efficient Antigen CrossPriming of Virus-Specific CD8 ${ }^{+}$T Cells. Cell Death Differ (2009) 16:991-1005. doi: $10.1038 /$ cdd.2009.8

70. Li Y, Wang LX, Yang G, Hao F, Urba WJ, Hu HM. Efficient CrossPresentation Depends on Autophagy in Tumor Cells. Cancer Res (2008) 68:6889-95. doi: 10.1158/0008-5472.CAN-08-0161

71. Li Y, Wang LX, Pang P, Cui Z, Aung S, Haley D, et al. Tumor-Derived Autophagosome Vaccine: Mechanism of Cross-Presentation and Therapeutic Efficacy. Clin Cancer Res (2011) 17:7047-57. doi: 10.1158/1078-0432.CCR-11-0951

72. Twitty CG, Jensen SM, Hu HM, Fox BA. Tumor-Derived Autophagosome Vaccine: Induction of Cross-Protective Immune Responses Against ShortLived Proteins Through a P62-Dependent Mechanism. Clin Cancer Res (2011) 17:6467-81. doi: 10.1158/1078-0432.CCR-11-0812

73. Ye W, Xing Y, Paustian C, van de Ven R, Moudgil T, Hilton TL, et al. CrossPresentation of Viral Antigens in Dribbles Leads to Efficient Activation of Virus-Specific Human Memory T Cells. J Transl Med (2014) 12:100. doi: 10.1186/1479-5876-12-100

74. Fan J, Wu Y, Jiang M, Wang L, Yin D, Zhang Y, et al. IFN-DC Loaded With Autophagosomes Containing Virus Antigen is Highly Efficient in Inducing Virus-Specific Human T Cells. Int J Med Sci (2019) 16:741-50. doi: 10.7150/ ijms. 31830

75. Hessvik NP, Overbye A, Brech A, Torgersen ML, Jakobsen IS, Sandvig K, et al. PIKfyve Inhibition Increases Exosome Release and Induces Secretory Autophagy. Cell Mol Life Sci (2016) 73:4717-37. doi: 10.1007/s00018-016-2309-8

76. Solvik TA, Nguyen TA, Lin H-ST, Marsh T, Huang EJ, Wiita AP, et al. Autophagy Cargo Receptors are Secreted via Extracellular Vesicles and
Particles in Response to Endolysosomal Inhibition or Impaired Autophagosome Maturation. bioRxiv (2021). doi: 10.1101/2021.08.12.456045

77. Duran JM, Anjard C, Stefan C, Loomis WF, Malhotra V. Unconventional Secretion of Acb1 is Mediated by Autophagosomes. J Cell Biol (2010) 188:52736. doi: $10.1083 /$ jcb. 200911154

78. Manjithaya R, Anjard C, Loomis WF, Subramani S. Unconventional Secretion of Pichia Pastoris Acb1 is Dependent on GRASP Protein, Peroxisomal Functions, and Autophagosome Formation. J Cell Biol (2010) 188:537-46. doi: $10.1083 /$ jcb.200911149

79. Dupont N, Jiang S, Pilli M, Ornatowski W, Bhattacharya D, Deretic V. Autophagy-Based Unconventional Secretory Pathway for Extracellular Delivery of IL-1beta. EMBO J (2011) 30:4701-11. doi: 10.1038/ emboj.2011.398

80. Zhang M, Kenny S, Ge L, Xu K, Schekman R. Translocation of Interleukin1beta Into a Vesicle Intermediate in Autophagy-Mediated Secretion. Elife (2015) 4:e11205.

81. DeSelm CJ, Miller BC, Zou W, Beatty WL, van Meel E, Takahata Y, et al. Autophagy Proteins Regulate the Secretory Component of Osteoclastic Bone Resorption. Dev Cell (2011) 21:966-74. doi: 10.1016/j.devcel.2011.08.016

82. Arbogast F, Arnold J, Hammann P, Kuhn L, Chicher J, Murera D, et al. ATG5 is Required for B Cell Polarization and Presentation of Particulate Antigens. Autophagy (2018) 15:280-94. doi: 10.1080/15548627.2018.1516327

83. Leidal AM, Huang HH, Marsh T, Solvik T, Zhang D, Ye J, et al. The LC3Conjugation Machinery Specifies the Loading of RNA-Binding Proteins Into Extracellular Vesicles. Nat Cell Biol (2020) 22:187-99. doi: 10.1038/s41556019-0450-y

84. Nowag H, Guhl B, Thriene K, Romao S, Ziegler U, Dengjel J, et al. Macroautopphagy Proteins Assist Epstein Barr Virus Production and Get Incorporated Into the Virus Particles. EBioMedicine (2014) 1:116-25. doi: 10.1016/j.ebiom.2014.11.007

85. Buckingham EM, Jarosinski KW, Jackson W, Carpenter JE, Grose C. Exocytosis of Varicella-Zoster Virions Involves a Convergence of Endosomal and Autophagy Pathways. J Virol (2016) 88:890-902. doi: 10.1128/JVI.02646-13

86. Taisne C, Lussignol M, Hernandez E, Moris A, Mouna L, Esclatine A. Human Cytomegalovirus Hijacks the Autophagic Machinery and LC3 Homologs in Order to Optimize Cytoplasmic Envelopment of Mature Infectious Particles. Sci Rep (2019) 9:4560. doi: 10.1038/s41598-019-41029-z

87. Chen YH, Du W, Hagemeijer MC, Takvorian PM, Pau C, Cali A, et al. Phosphatidylserine Vesicles Enable Efficient En Bloc Transmission of Enteroviruses. Cell (2015) 160:619-30. doi: 10.1016/j.cell.2015.01.032

88. Robinson SM, Tsueng G, Sin J, Mangale V, Rahawi S, McIntyre LL, et al. Coxsackievirus B Exits the Host Cell in Shed Microvesicles Displaying Autophagosomal Markers. PloS Pathog (2014) 10:e1004045. doi: 10.1371/ journal.ppat.1004045

Conflict of Interest: The author declares that the research was conducted in the absence of any commercial or financial relationships that could be construed as a potential conflict of interest.

Publisher's Note: All claims expressed in this article are solely those of the authors and do not necessarily represent those of their affiliated organizations, or those of the publisher, the editors and the reviewers. Any product that may be evaluated in this article, or claim that may be made by its manufacturer, is not guaranteed or endorsed by the publisher.

Copyright $(2022$ Münz. This is an open-access article distributed under the terms of the Creative Commons Attribution License (CC BY). The use, distribution or reproduction in other forums is permitted, provided the original author(s) and the copyright owner(s) are credited and that the original publication in this journal is cited, in accordance with accepted academic practice. No use, distribution or reproduction is permitted which does not comply with these terms. 